\title{
Blockchain, IoT and Fog Computing for Smart Education Management
}

\author{
Sakchai Chaiyarak, Alongkorn Koednet, Prachyanun Nilsook \\ Suan Dusit University and King Mongkut's University of Technology North Bangkok \\ Thailand
}

Received: April 13, 2020. Revised: May 26, 2020. Accepted: June 23, 2020. Published: July 21, 2020.

\begin{abstract}
The objective of this research is to present the use of blockchain technology, the internet of things and fog computing to develop the potential of school management for smart education. By using the blockchain to record and store various pieces of information the organization will create credibility of administrative data in all departments and will reduce corruption. Data can be examined transparently, especially the financial and budget management and procurement of durable articles. Regarding the academic work and registration, it can be used to store learners' information, educational history, information of enrollment, academic results, and participation in the various activities of the educational institutions. It can create credibility in the management of information about content, learning and ability assessment results that students receive, and these can be recorded and stored in a blockchain that can be safely distributed. In addition, IoT and fog computing are integrated with AI systems embedded in various modern devices to be applied in environmental management and smart education management. IoT and fog computing help to support and respond quickly to questions about the use of all types of equipment for real-time management of executives, personnel and students, as well as creating new work and learning styles that can solve the situation of dangerous communicable diseases, such as the COVID-19 situation, or can solve emergency situations that will emerge in the future by working and studying from home. It can organize and share resources for work and learning together to access the organization from outside anywhere and at any time.
\end{abstract}

Keywords - Blockchain, Internet of Things (IoT), Fog Computing, Artificial Intelligence, Smart Education Management

\section{INTRODUCTION}

$\mathrm{T}$ ODAY, the world has changed dramatically and developed into the era of $5 \mathrm{G}$ communication, which is the era of application development and various platforms via the internet of things (IoT). There is a simulation of virtual reality (VR). There is a development of technology to combine the real world and virtual reality together (Augmented Reality: AR). There are vehicles that can self-drive automatically (Autonomous Vehicles). Computers can communicate by themselves (Machine to Machine: M2M) [1]. There are robots, like artificial humans, that can learn, communicate, and imitate human behavior. There has been a rapid change in modern technology in the last few years, especially in the metropolitan areas in many countries. They have developed into smart cities to improve the quality of life for people by using IoT, cloud computing and blockchain, which are technologies that can provide services and which users can access safely and efficiently [2]. The smart city model uses advanced technology for driving, such as IoT, big data, cloud computing and other technologies combined with smart management to improve cities and adjust to a comfortable lifestyle. Its characteristics are smart home, smart transportation, smart health care and smart climate control. IoT will enable users to access the smart city through cutting-edge devices and technology from smartphones, personal wearables, and signal detection devices. Challenges in computer system development of smart cities are to check the equipment and user rights that are trusted. Access security and protection against malicious attacks can allow connected devices to access the system quickly and respond to the needs of many devices at the same time by using edge computing technology as an intermediary between IoT and cloud computing [3]. In addition to the development of the smart city, there is also smart manufacturing industry, smart developments which apply edge computing together with blockchain technology. The smart manufacture is at the heart of the modern manufacturing industry in the industrial 4.0 era. Smart or intelligent production operations that are successful must be supported by outdated information, data, and processing technology. Therefore, blockchain technology, AI and IoT play an important role in the development of intelligent systems within the manufacturing industry to ensure safety, a quick response to the control of production equipment and use blockchain for storing and verifying device data, as well as validating service and production transaction rights [4]. In terms of agriculture, the technology has been applied to be developed into smart farming by using IoT and intelligent processing technology to revolutionize agriculture in the $21^{\text {st }}$ century. Smart devices are used extensively among farmers or entrepreneurs and are used in a variety of ways, such as to analyze real-time plant growth and amount of soil moisture, and use of a remote control aircraft (drone) to help with tasks such as spraying pesticides and automating farming. It was developed using basic IoT technology to maintain and monitor smart farming with cloud computing and big data [5].

In the area of educational development in the $21^{\text {st }}$ century, there must be a vision and a focus on educational reform for the future. This will involve the use of innovation and modern scientific and technological development. When applying cloud computing and IoT to education management, it will be able to solve many problems, such as the development of system 
architecture for green university resource planning on cloud computing to promote sustainable and environmentally friendly management as well as participation in reducing the environmental, economic, social and health problems resulting from the use of resources, as much as possible [6]. It can also be used for supply chain management (SCM) for higher education institutions (HEIs) to help manage work processes in the organization in accordance with real situations. This will be especially true in the management of finance and budgets, the behavior of personnel in the organization and the needs of service users in accordance with good governance principles. Therefore, IoT plays a very important role in the development of new technology in education management [7]. The use of IoT in education allows teachers and students to learn and participate in activities through tablet devices, smart phones, or VR wearable glasses. It can be used to manage learning remotely via a webcam and connection to the internet. IoT can also be used with a security system to cover all areas via CCTV and signal detection equipment, used for face recognition and to check the person's information from the database. In addition, IoT allows administrators to access and edit information remotely [8]. The most important challenge for management, in order to lead to smart education, is the development of management systems by using the latest modern technology to be applied for laying the basic structure and creating educational innovations in the future. The interesting direction is that Blockchain technology is used in conjunction with the Internet of Things (IoT), Fog Computing and Artificial Intelligence (AI) for educational management. AI is the use of artificial neural systems in technology and devices that can develop educational management intelligently.

\section{SUMMARY OF LiterATURE REVIEW}

The author presents the essence of "Blockchain, IoT and fog computing for smart education management", which occurs from the analysis and synthesis of relevant documents and research as follows:

\section{A. Blockchain}

Blockchain technology provides security and it can reduce transaction costs or asset transfers between individuals and reduce interference from others [9]. It helps to create a distributed environment for transactions and data that are not under the control of an intermediary or an organization. Any information or transaction that has been completed is permanently recorded in the ledger and can be proven or verified [10]. It is considered a new architectural framework for the storage and data exchange between network members [11]. In addition, the ability of the blockchain technology used to save data and store on ledgers is reliable. It can create opportunities for prevention of corruption, transparency and more confidence in the government [12]. The idea of blockchain began with the use of bitcoin encryption, introduced by Satoshi Nakamoto in 2008 [13]. The initial use of blockchain was the use of peer-to-peer ledgers for registration for digital currency transactions. Its purpose was to reduce intermediaries or other people and to allow users to conduct transactions directly among themselves [14]. Nowadays, blockchain is gaining more attention in its implementation because it is a reliable distributed ledger account system. It is transparent and can be linked globally, which will help facilitate the efficient management of information [15]. Blockchain is able to record data that has been approved by both parties and is permanently stored. It can be proven and verified by distributing copies of the data or transactions to the user group to recognize the corresponding data. No one can go in to manage, control or edit new information by themselves without the approval of members. Therefore, the blockchain-based system is more transparent and more reliable than other data storage formats [16] because every user has a copy of the ledger account and that account will show the history of all transactions. Therefore, it is not possible to fraudulently change information. If wanting to edit new information, it must be approved or have the consensus of the other members in order to edit and place new information instead of the original information [17]. The development of smart cities uses blockchain in conjunction with IoT to record data of connected devices in the network to prevent the modification of unrelated and unauthorized third parties and to ensure the data that are transmitted from real-time signal detection equipment is properly licensed to access networked devices. Blockchain also allows connected devices in the IoT system to communicate automatically and make joint decisions [18].

In terms of educational management, blockchain helps learners and academic institutions to record academic results and guarantee results through a secure network. It allows learners to be able to own records of results and information that has been independently certified by the institution [19]. There is research to apply blockchain to be used as an educational database such as the collection of educational history and academic results in tertiary education in Europe, in order to review conveniently educational information of students applying for work. Currently there are many online education platforms, such as MOOCs, Coursera, XuetangX and others. In addition to requiring courses to create an internet learning environment that shares multimedia learning resources, there are risks in managing digital rights, such as violations of access to resources used in multimedia learning as well as the credibility of online transcripts. Therefore, digital learning rights management systems using blockchain have been introduced, including architecture, a new network for sharing and managing multimedia resources of online learning based on a combination of personal blogs and connection to the public. It has been proved that it can really solve problems. There is a safe storage system and it is easy to check transcripts [20]. The management of higher education at present has the form and methods of both theoretical and practical learning management in many ways and these can be both formal and informal. It is difficult to check the level of knowledge and skills of a learner when compared to the information contained in the education certificate and the credibility issues of that document when it has not been verified and confirmed by the institution. For this reason, tertiary education requires the development of new tools to improve the educational management system by using blockchain to support the reliability of data management in both the curriculum and the 
evaluation results. This will then show that the learner has been approved and saved on the blockchain in order to reduce the problem of continuing to check educational information from employers or entrepreneurs in the future [21].

\section{B. Internet of Things (IoT)}

Modern internet in the new era can integrate all the technology together and can detect the operation and create the network with various services dynamically. Such devices are widespread in modern life and can be found in homes, public transport systems, expressways, and vehicles. IoT applications can work across different devices. It can enable a variety of analyses and manage complex interactions between devices. Therefore, IoT equipment and services can address various challenges, including infrastructure, building management systems, transportation management and electronic health systems [22]. There is a multiplicity of intelligent technology devices that can be integrated with IoT, to support the work of people. Those genius devices are inevitably important to human life [23]. They emerged in rapidly growing smart cities. They are equipped with a control signal detector via IoT. It allows the devices to connect together and can be used automatically [24]. IoT is used to develop and automate agriculture. It reduces human labor and can control work remotely. It has turned out to be an intelligent agriculture model, using the architecture and operation of the network with cloud computing to store data and using that data to analyze and consequently reduce problems and create security in agriculture. We can use the application to control the operation via smart phones and signal detectors developed for agricultural management and which have been included in policies of many countries to create new agricultural standards [25]. IoT is used to create security for agriculture with blockchain by designing agricultural architecture based on green IoT and surveying smart agriculture management which analyzes security-oriented approaches with blockchain and determines algorithms that are consistent with IoT applications. It is an appropriate method for agricultural use based on green IoT [26]. Blockchain technology is used to allow IoT access by designing and installing as fabric-iot access control using hyper, ledger fabric and attributed based access control (ABAC). Distributed architecture, fabric-iot is able to track usage and control access to applications dynamically. The rapid development of IoT requires a higher standard for distributed access control. Therefore, blockchain has the advantage of being able to respond to such controls with features such as decentralization, data encryption, scalability, and unauthorized editing of data. Currently, blockchain has developed into version 3.0, able to be used as a basis for smart terms. There is a more powerful function. Many scholars have suggested ways to control IoT access using blockchain's application [27]. 5G technology can greatly expand the service of IoT and respond to the use of all devices in real-time quickly. The use of fog computing in the system helps to support faster operations because centralized data management that relies on remote data integration from cloud computing is unable to respond effectively to IoT operations, for example, the use of low latency and the need to respond quickly to the device.
Therefore, fog computing is used to solve problems and has gained more popularity in the past. It can support IoT operations by reducing time and increasing workloads more directly than working with cloud computing [28]. IoT is an important network connection for human interaction through embedded communication. Currently, IoT is used in many areas because it can transfer large amounts of data quickly. It can support many devices at the same time. There is a low latency in response to commands. It helps people to control the operations of various devices remotely. Therefore, it has been developed to be used primarily in Industry 4.0 to reduce the risk and safety of human work [29].

IoT is becoming a technology that can change the world (Disruption) especially for users in big cities. The rapid rise of smart devices and the improvements embedded within the various electronic devices is increasing. Therefore, the network area must be expanded to cover for the connection to use intelligent devices and a device for detecting all types of signals together without restrictions [30]. The concept of using IoT to be the center of everything starts to become more real, such as autonomous cars, intelligent environment control, highdefinition video live broadcasting, health care in an electronic way and many more. These applications need more data. They use a large bandwidth. They use the speed of data transfer. They have a low latency and they can support the connection of many devices at the same time. The emergence of the IoT has changed the world. It is a communication that allows fast connection between devices. The key goal of IoT is plug and play technology that is easy to use, convenient and can control and configure settings for accessing devices remotely without restrictions [31].

\section{Fog Computing}

The modern technology of new information technology (New IT) stimulates the development of many smart devices. In a smart work environment, there are many devices that must be connected to the internet and send and receive large amounts of data. Intelligent computing on cloud computing makes it easier to collaborate online and can use a lot of data to analyze and help computers learn from those big data. However, applications that must be connected to IoT and must be used in real-time, they need high speed and a low response time. Fog computing is more responsive to device connectivity than to operating directly with cloud computing [32]. Fog Computing is efficient in allowing it to recognize the location of the device and has the speed to connect the operation of the related equipment. An important example is remote control of automobiles that require tracking the location of connected cars via wireless. Therefore, real-time operation and time delay in response must be very low so that safety can be assured. Fog Computing is suitable for controlling devices through the network and wireless signal detectors installed around a geographical area [33]. The definition of "fog computing" first occurred in 2012, with CISCO designated as a virtual platform that provided data processing and storage services on the network between the terminal device and the data center of cloud computing. Fog computing is the same type of processing 
as edge computing, which reduces direct processing time with cloud computing and increases the response speed with endpoints. The goal of fog computing is to be a connection between the cloud to things. Therefore, fog computing is not just a small addition to cloud computing, but it is an intermediary system that connects the cloud with IoT to increase system speed and efficiency [34]. The development of the IoT has resulted in unmanned vehicle technology that will greatly facilitate people's travel and reduce traffic congestion on the roads. Fog computing can meet unlimited possibilities for vehicle control with the internet of vehicles (IoV). Fog computing will store intelligent navigation services from a cloud server. It will allow users to control remote computer systems in vehicles through a fast and secure network [35]. Fog computing is a new way to expand the cloud computing platform, but there are differences in the distribution of capabilities. In addition, fog computing can process large amounts of data completely and can be installed on different devices. These features make it an ideal platform to use to reduce time and work quickly [36].

Fog computing is present in education. It is used to improve real-time procedures in education management and to enable access to facilities. Modern media and technology can be scaled to the needs of each institution. For the future, the use of internet and online data will increase the number of users such as personnel and learners who want to access the database management system and online learning management through the website and database of organization information. Fog computing enables endpoints to be connected for efficient online learning and training. It can reduce travel expenses to the classroom and help promote educational operations and build a fast platform, and it will be a technology that can be used for educational development in the future [37]. Today, many universities and educational institutions have developed information technology to enhance and develop educational strategies to encourage more students. E-learning and learningon-the-go are the technology formats that universities use to make education systems more flexible. E-learning is gaining popularity worldwide and the number of learners enrolled in online courses is increasing. This trend is possible because of cloud computing. In the context of education on cloud computing, the safety factor in sharing educational content is important and poses many challenges. For example, access checking and content security systems. Therefore, there is an idea to use architecture in the form of a user-fog-cloud to enable more direct services to users. It can improve the efficiency of learning and save the cost of education. The fog computing, elearning development concept will provide benefits for teachers and learners with the flexibility of content presentation and online learning collaboration. It can conveniently recognize locations from access between teachers and learners and to access and share shared learning resources online in real-time conveniently [38].

\section{Artificial Intelligence}

Artificial intelligence (AI) was first introduced in 1955 by John McCarthy, an American computer and intellectual scientist who demonstrated the progress of science and engineering in the creation of intelligent machines. It works to imitate human behavior and learn like humans. McCarthy's initial project was to develop AI by creating computer programs that could play checkers and compete with humans. It can explain variables and mathematical assumptions throughout the period from 1990 to the present. The utilization of AI has been developed in large numbers and has become an important part of society today and will be in the future [39]. It is a development that allows computers to show intelligent behaviors such as learning, speech and human language, planning, reasoning, problem perception, movement and organization of before and after like humans [40]. It is the development of computers to understand intelligence and create learning mechanisms that can respond in a similar way to humans. AI will look like a robot that can recognize the language, images and can process the human language and is a form of intelligent systems. It is the development of technology in order to be able to learn and make decisions on complex work by itself [41]. It is the creation of computerized machinery to mimic human behavior and cognitive processes. It can learn, reason, and use rules to reach certain conclusions in order to make decisions about problems. The unique characteristics of AI consist of intelligent systems that can make decisions based on information about specific areas of vision and sound and can sense and touch just like humans [42]. AI is a progressive technology that changes society, economy and helps support work. Examples of applications using AI systems include social networks, unmanned vehicles, chatbots, voice assistants, internet search engines, robot operators, etc. These systems can be installed and embedded into devices or as a type of program that can be installed later. The amazing ability of AI helps to change the way of life of people in society through modern technology devices [43].

Nowadays, AI has been applied in education management to analyze work systems, predict behavior of personnel within the organization, analyze learning behavior and evaluate learners' learning. It is used as a public relations agent to provide information and answer questions automatically instead of personnel or staff, Moreover, AI is used to analyze data in research and human resource management (HRM) [44]. For communication systems and network efficiency improvements in the $5 \mathrm{G}$ era, including IoT, $\mathrm{AI}$ is used to help analyze data calculations, send, and receive data and use bandwidth with edge computing to connect to wireless networks. It can reduce the delay in accessing the work because the bandwidth is limited while the number and complexity of the work in the network are increasing rapidly. Therefore, the most efficient method for network service providers, who must meet the demand for urgent use according to the different rights of users to allocate network channels according to the usage rights, is very important. Other than that, the variety of tasks in the network system is still too complicated to be managed. Therefore, AI and AI algorithms are used to manage and decide complex problems automatically [45]. From the beginning, AI was just a concept and in the imagination of screenwriters but, these days, these concepts and ideas have become true in 
society due to the development of advanced technology and it has an influence on the daily lives of people. Although there are many definitions of $\mathrm{AI}$, different definitions indicate that $\mathrm{AI}$ is a continuous construction of machinery or technology that can think and analyze like humans. It can think, solve problems, and learn languages in order to create complex understanding as well as human intelligence. AI allows many people to live their daily lives comfortably via smart phones and modern technology devices, which are installed as intelligent systems embedded in those modern technology devices, including work programs of various computer systems. AI quickly solves complex problems for humans. It is capable of diagnosing, treating, surgery and caring for human health or even knowing and recognizing problems and then being able to create guidelines for appropriate solutions. In addition, it makes things, which are difficult or dangerous, easy, and safe for humans. Therefore, AI has rapidly developed and expanded the scope of business and industry applications, including the use of organizations in the government sector, and it is part of important government policies for use in the drive for national development, by using the intelligence of machinery and robots that can learn about work in depth [46].

\section{E. Smart Education Management}

Smart education management uses modern technology in enterprise management, such as IoT and cloud computing. Big data and AI applications technologies are the cornerstones of a smart education management model designed to meet the needs of users in a sustainable environment with the nature of the organization. To achieve this goal, each component must be involved in a joint operation and focus on the use of IoT through a signal detection device and automatically interact with users. That interaction occurs directly between the device and the user. Data will be sent to cloud computing to process and respond to usage commands [47]. The development of education with the application of IoT will increase efficiency and support a smart higher education institution. The key step in system development is the analysis of the organization architecture and system design that brings IoT into use to manage the organization's infrastructure system [48]. Smart education management is a type of management and learning environment that combines operations with services based on the internet and through various technology applications. For example, cloud computing and network technology can be used to connect and integrate human operations with machine equipment. Management of the school can be driven by a form of big data to help administrators make effective decisions. The digital platform is used to provide comprehensive information services through a flexible and secure network to support various tasks and uses technology to monitor the management of the school environment. The development of wired and wireless networks covers the area of the school, using the integrated network distribution platform to help administrators manage information about students, teachers, curriculum management and education management intelligently. Students will be able to experience online learning by being able to learn more by themselves and choose courses to learn according to their interests. In addition, the system can create personalized services that effectively respond to the needs of administrators, personnel and all learners [49].

\section{RESULT AND DISCUSSION}

Based on the study of blockchain, the internet of things, fog computing, artificial intelligence, and smart education management, the authors used document analysis and the synthesis of relevant keywords. See Table 1.

Table 1. Synthesis of keywords

\begin{tabular}{cll}
\hline No. & \multicolumn{1}{c}{ Keyword } & \multicolumn{1}{c}{ References } \\
\hline 1 & Blockchain & {$[9][10][11][12][13]$} \\
& & {$[14][15][16][17]$} \\
& & {$[18][19][20][21]$} \\
\hline 2 & Internet of Things (IoT) & {$[22][23][24][25]$} \\
& & {$[26][27][28][29]$} \\
& & {$[30][31]$} \\
\hline 3 & Fog Computing & {$[32][33][34][35]$} \\
& & {$[36][37][38]$} \\
\hline 4 & Artificial Intelligence (AI) & {$[39][40][41][42]$} \\
& & {$[43][44][45][46]$} \\
\hline 5 & Smart Education & {$[47][48][49][50]$} \\
& Management & {$[51][52][53][54]$} \\
& & {$[55]$} \\
\hline
\end{tabular}

The author summarized and presented interesting examples of articles and research in educational development in order to move towards smart education management as follows.

1. Smart Campus based on IoT Technology [50]. The main objective of this research is to experience success in smart management and services on campus by applying IoT to organization management and learning by providing access to external learning facilities. This research provides recommendations and presents the results of current research analysis of smart campuses and compares the complexities of data integration of traditional campus services with smart genres. After the analysis of the situation data was completed, the researchers designed an algorithm to provide services for the smart campus and an algorithm based on data which, in turn, was based on previous research in the situational framework for smart campuses. When compared to traditional campus platforms, it found that smart campuses were able to manage information more efficiently than a facilitating service. It is the development of management styles on the campus to be faster.

2. The model of the university's intelligent campus development was enabled through IoT technology [51]. It presents a combination of IoT in education, a form of communication through the internet between controllers for signal detection equipment and physical devices and proposes guidelines for using modern technology. In order to change the style of education of the university at a high level by integrating various devices with the wearable signal technology through Cloud Computing, IoT will be able to configure a variety of parameters for university management. It will be able to promote the opportunity to develop into a smart organization. This research focuses on the creation of the smart classroom and smart parking systems, as well as the development of smart 
education using IoT and cloud computing.

3. The Smart University and the use of computers that emphasize university services [52]. This research presents technological changes that are catalysts for reform of traditional universities. When talking about the promotion of artificial intelligence (AI) and smart learning platforms in MOOCs, it was mentioned about traditional universities that have used human expertise for a long time. There must be a change in the operation of the university at a high level to change according to evolution and social progress. For these reasons, there has been a push for the transition to a university into a smart university system (SUS), which is in line with the emergence of the smart city and the development of information technology infrastructure. This paper presents an examination of the role and participation of service-oriented computing (SOC) in order to determine the details of the smart university for providing smart services to all the university's stakeholders and in the field of self-access online education according to the concept of service that is a key component of the smart university system.

4. Examining academic credits and issuing education certificates in the Brazilian educational system [53]. It has been proposed that, at present, the Brazilian educational system occurs in a semi-use and non-computerized manner to store information for qualification certificates in the education system. Digital storage is more secure, and it can reduce the burden of checking or searching for documents. It can save storage space and can reduce the risk of loss and reduce the chances of forgery. Therefore, there must be a transparent and reliable process for all parties involved to solve problems. This article presents suggestions and procedures for digitizing Brazilian higher education qualifications by presenting transparent models based on Blockchain technology. The institution will process student enrollment and record credits for learned courses using the Blockchain and allow access to information to be public for agencies within Brazil. It allows students to save information on trusted and certified qualifications from educational institutions and a copy of the historical data distribution account with encryption to be safely public.

5. Review about the development of a smart education system [54]. It presented the essence about smart educational management, that it is a process that uses modernization of information technology to reform and develop education in areas such as education management, teaching and educational research. It emphasizes that education is the foundation of national development. Therefore, it is very important to change the concepts and forms of education in the past by reforming education and improving the quality of education with innovation and using modern information technology to manage and present a guideline for smart education in China. It is an important form of education development in the era of technology changing education systems. It consists of 1) Smart Campus, it is the creation of a genius digital campus, with the characteristics of a genius campus consisting of five important points: (1) fast and widespread broadband internet access, (2) real-time and comprehensive smart environment usage, (3) integration of business applications and intellectual technology,
(4) big data analysis with smart systems, (5) intelligent and friendly service and convenient for individual use. 2) Intelligent tutoring system (ITS). It is a software system that promotes appropriate teaching strategies based on the knowledge, understanding and skill levels of learners. 3) Big data in education (BDE). It is an analysis of all behavioral data received by students. It is an activity log for daily analysis based on steps and situations. It is student behavior data obtained from online learning platforms and digital curriculum management platforms. 4) Knowledge graph. It is a representation of a structural knowledge database to explain physical relationships in the form of symbols. It can link knowledge from questions and gather relevant information. It makes computers more efficient in analyzing data and can advise users wisely. 5) Educational robot. It is important technology for robots for education, including artificial intelligence, voice recognition and bionics. There are currently seven directions for robotics research for education, including facial features, hearing ability, human language ability, speaking ability, vision ability, emotions and feelings and the ability to interact naturally. Problems in integrating robotics for education have four areas: lack of platform, simple curriculum management, lack of interesting learning content design, lack of linking learning with real working conditions and the lack of research related to robotics in educational applications. Developing robots for education in the future needs to start from a realistic perspective. There must be good strategic planning and expansion of the application to support all platforms. There is a need to set clear goals for robotics development for education. 6) Virtual teachers: the advancement of technology in the $21^{\text {st }}$ century is widely applied to virtual reality technology and human virtual technology in education or continuously developing virtual teachers. Creating a three-dimensional virtual teacher with realistic images and with cheerful expressions by simulating movement, expression, and the teaching process of real teachers in a three-dimensional virtual learning environment can be created by computers. Currently, intelligent virtual teacher systems include the threedimensional virtual teacher system and the dialogue in the language of the virtual teacher system. Key technologies used include Intelligent Agent technology, virtual display technology, virtual human technology, speech synthesis technology and natural language processing. Virtual teachers have various behavioral expressions and realistic emotional expressions. Therefore, the important thing in creating a virtual teacher is to develop awareness of the changes in the surrounding environment and develop virtual teachers to mimic the teaching behavior of real teachers intelligently. 7) Personalized education: the modernization of educational resources provides learners with access to a variety of personal learning resources. The development of cloud computing for education increases the flexibility of the learning space and the virtual learning community. It can meet the needs of distant learners to be able to continually cooperate and communicate with each other. The online learning model helps to keep track of learning outcomes, record and analyze learner data and diagnose personal learning precisely. The development of 
personalized education in the 21 st century will add value and accumulate educational information and create lifelong learning options for learners.

6. Smart vocational college: A case study of Dalian vocational college [55]. The basic conceptual framework is developed into a smart campus in four steps: 1) improving the infrastructure for high-speed technology networks by using IoT to create a stable and comprehensive network environment. 2) Data source development by using Big Data Analysis to design resource management systems and improved work efficiency. 3) Smart application development and service model, consisting of (1) Smart learning for students and instructors using collaboration from Netease Cloud Classroom and MOOC of Chinese university and, in the application, can add teaching information such as lessons, audio, video and other materials based on traditional learning basics. It helps teachers create standardized courses and manage classes using modern technology with a networked learning platform. Students can interact with the instructor from a distance at any time. The cloud classroom can create discussion groups and define discussion points for communication between students. (2) Smart life for learners, instructors, and staff by improving the authentication system with fingerprint authentication and facial recognition platforms for use in various colleges. Therefore, ID cards, fingerprints and faces can be used for identification in attendance, operations, food purchases and other activities. (3) Smart Research for teachers and staff by using digital platforms to assist personnel in research to reduce paper use and to use smart technology to analyze research data and search data and adjust the systems and steps in the research process to be in the form of online systems. (4) Smart Management for organization executives using basic infrastructure technology to manage work systems, manage finances and budgets using online document systems to support teaching and learning services with smart digital systems. (5) Smart decision for mid-level executives to use for communication and data analysis for decision making, receiving orders, and transferring and driving operations through cloud computing. (6) Smart sharing for learners, instructors, and external organizations, such as providing information and online consultation, sharing open learning resources through digital platforms and websites. (7) Smart school-enterprise cooperation for organizations, learners and external establishments using digital platforms as a channel of communication and designing collaborative work practices online. 4) Maintenance and security systems, high-speed network usage and intelligent alarm systems, keeping student data and server computers safe, especially financial data, registration, and certificates of student qualifications.

From the synthesis of relevant information, the author summarizes and designs it as a picture to show an overview of the relationships of the blockchain-based model, the internet of things and the mist processing to manage education wisely (Smart) as shown in the figure 1, It shows the concept of educational management design using blockchain as the center of the education system to save and store encrypted account information distributed and categorized according to the scope of the school in five areas as follows 1) Smart learners and teachers by developing a digital platform to record instructor information, learners, learning management and transcripts with blockchain. 2) Smart academic and research by developing digital platforms to help with academic operations, academic services, and research of personnel to reduce the use of paper and use smart technology to help analyze academic data courses. Research and data search and adjusting the operational process to be digitized and collect academic and research data with blockchain. 3) Smart management, using infrastructure technology to manage work systems, manage finances and budgets and make decisions based on big data analysis. To use online-based management to help save the necessary budgets, such as reducing energy consumption with IoT structure, video conferencing and storing transparent corporate management data with blockchain by using digital technology strategies to support teaching and learning and various services. 4) Smart services and supported services, the development of an opensource learning resource management service through a blockchain encryption account to provide information, answer questions or provide automated consultation through a variety of communication formats. 5) Smart tools and infrastructures, the development of digital technology infrastructure and tools necessary for managing and maintaining security within the organization with IoT and using blockchain to check permission for access to various infrastructures. Fog computing is used as an intermediary connecting data processing with big data on cloud computing to help stable and fast communication and access to various systems based on $5 \mathrm{G}$ technology. IoT structure can control the operation from smart phones and various devices by installing signal detection equipment within the equipment of the organization's infrastructure so that it can control automatically. It should also be environmentally friendly, safe and can save energy. Therefore, blockchain, the internet of things and fog computing for smart education, based on this concept and conclusion, divides the system under IoT infrastructure into four levels, which are 1) The physical layer consisting of the scope of the work system in the organization in all five areas, 2) The blockchain layer, which works according to the form and structure of the blockchain. 3) The fog layer which is the processing and storage of data according to the standards of fog computing. It is an intermediary for connecting the processing with cloud computing. 4) Cloud layer. 


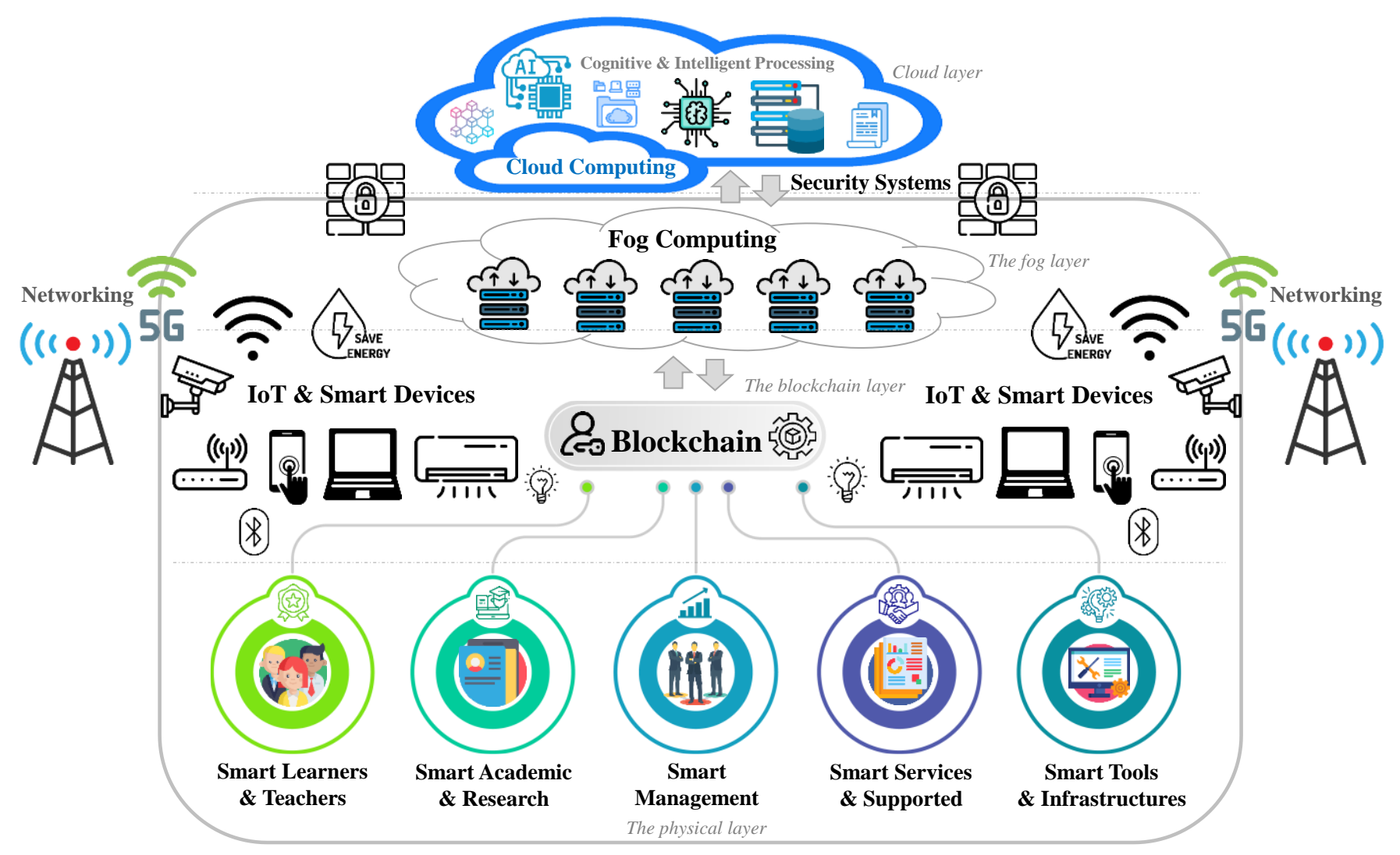

Fig. 1 Architecture of blockchain, IoT and fog computing for smart education management

\section{CONCLUSION}

Smart education management is a form of educational management that uses digital technology to help manage the infrastructure to enable resource management, strategic planning management and development of modern teaching styles along with digital platforms. Smart educational management, by applying blockchain, IoT and fog computing, can apply modern technology in modern times to be used as an educational development infrastructure and educational innovation. Blockchain is used for recording and storing various consensus-based data sharing within educational institutions. It will be able to build reliable data management in all departments. It can reduce fraud and be able to examine information transparently, especially in matters relating to finance and budgets, procurement of durable goods and educational quality assurance work. In terms of the academic work and research, it can be used to develop teaching and learning on the digital platform, store information about a learner's history, educational history in different classes, registration information, participation in the curriculum and institutional activities, academic achievement and the education certificate. Blockchain is the center of the education system so students can save their educational history, as approved by the school and their results and can publish with an encrypted account which is a system that is safe and has a process to check the accuracy from the institution. Employers or entrepreneurs can access and check the information of each student. Developing infrastructure with IoT and fog computing can create intelligent educational environments to meet the needs of all kinds of devices for the management of personnel, It can help to support and respond quickly to questions about the use of all types of equipment for real-time management of executives, personnel and students, as well as creating new work and learning, can organize and share resources for work and learning together to access the organization from outside anywhere and at any time. They will be able to communicate and collaborate more effectively. It connects the CCTV inside the building to detect abnormalities and security by automatic control and operation via a smartphone. It connects signal detection equipment to analyze environmental conditions and control energy efficiency appropriately. In addition, it can support online real-time education and allow learners to connect and access remote learning systems conveniently and quickly. It can help reduce travel costs and can create new work and learning styles that can help solve dangerous epidemics, such as the COVID-19 situation, or can solve emerging emergency situations in the future by working and learning from home. In terms of artificial intelligence, AI is developed and designed to be installed and embedded within all modern technology equipment, including programs or online processing that automatically respond to work. It is the use of artificial neural systems in technology and devices that can develop educational management intelligently, it can analyze work systems, predict behavior of personnel within the organization, analyze learning behavior and evaluate learners' learning, can analyze the work to reduce errors and can be used to promote learners' learning in various digital platforms. In addition, it is used as an agent for public relations to provide information, answer questions or give recommendations that 
are correct and appropriate automatically. The researchers believe that the documentary research that synthesizes the relevant keywords will lead to the architectural concepts. This will be a crucial idea used in the future experimental research, which might use blockchain, Internet of things (IoT), and Fog computing to smartly develop and upgrade the educational management. Also, the research in the future should use more big data to thoroughly run the studies and to be able to effectively follow up the educational success.

\section{ACKNOWLEDGMENT}

This research was supported by Dr. Sittiporn Iamsen, Dean of Faculty of Education, Suan Dusit University and Division of Information and Communication Technology for Education, Faculty of Technical Education, King Mongkut's University of Technology North Bangkok. The researchers would like to show appreciation in being supported for this research until it was accomplishment very well.

\section{REFERENCES}

[1] S. K. Sharma, I. Woungang, A. Anpalagan, and S. Chatzinotas, "Towards Tactile Internet in Beyond 5G Era: Recent Advances, Current Issues and Future Directions," IEEE Access, vol. PP, no. ii, pp. 1-1, 2020.

[2] S. Hakak, W. Z. Khan, G. A. Gilkar, M. Imran, and N. Guizani, "Securing Smart Cities through Blockchain Technology: Architecture, Requirements, and Challenges," IEEE Netw., vol. 34, no. 1, pp. 8-14, 2020.

[3] B. Wang, M. Li, X. Jin, and C. Guo, "A Reliable IoT Edge Computing Trust Management Mechanism for Smart Cities," IEEE Access, vol. 8, pp. 46373-46399, 2020.

[4] C. K. M. Lee, Y. Z. Huo, S. Z. Zhang, and K. K. H. Ng, "Design of a Smart Manufacturing System with the Application of Multi-Access Edge Computing and Blockchain Technology," IEEE Access, vol. 8, pp. 28659-28667, 2020.

[5] M. Gupta, M. Abdelsalam, S. Khorsandroo, and S. Mittal, "Security and Privacy in Smart Farming: Challenges and Opportunities," IEEE Access, vol. 8, pp. 34564-34584, 2020

[6] J. Nookhong and P. Nilsook, "Green University Resource Planning on Cloud Computing,” Int. J. Inf. Educ. Technol., vol. 7, no. 10, pp. 722-727, 2017.

[7] W. Kuandee, P. Nilsook, and P. Wannapiroon, "Asset supply chain management system-based IoT technology for higher education institutions,” Int. J. online Biomed. Eng., vol. 15, no. 3, pp. 4-20, 2019.

[8] H. D. Mohammadian, "IoT - a Solution for Educational Management Challenges," in 2019 IEEE Global Engineering Education Conference (EDUCON), 2019, pp. 1400-1406.

[9] F. Tschorsch and B. Scheuermann, "Bitcoin and beyond: A technical survey on decentralized digital currencies," IEEE Commun. Surv. Tutorials, vol. 18, no. 3, pp. 2084-2123, 2016

[10] M. Turkanović, M. Hölbl, K. Košič, M. Heričko, and A. Kamišalić, "EduCTX: A blockchain-based higher education credit platform," IEEE Access, vol. 6, pp. 5112-5127, Jan. 2018.

[11] E. Funk, J. Riddell, F. Ankel, and D. Cabrera, "Blockchain technology: A data framework to improve validity, trust, and accountability of information exchange in health professions education," Acad. Med., vol. 93, no. 12, pp. 1791-1794, 2018

[12] F. R. Batubara, J. Ubacht, and M. Janssen, "Challenges of blockchain technology adoption for e-government: A systematic literature review," ACM Int. Conf. Proceeding Ser., 2018.

[13] P. Cui, U. Guin, A. Skjellum, and D. Umphress, "Blockchain in IoT: Current Trends, Challenges, and Future Roadmap," J. Hardw. Syst. Secur., vol. 3, no. 4, pp. 338-364, 2019.

[14] A. Alammary, S. Alhazmi, M. Almasri, and S. Gillani, "BlockchainBased Applications in Education: A Systematic Review," Appl. Sci., vol. 9, no. 12, p. 2400, Jun. 2019
[15] T. K. Mackey et al., “'Fit-for-purpose?' - Challenges and opportunities for applications of blockchain technology in the future of healthcare," BMC Med., vol. 17, no. 1, pp. 1-17, 2019.

[16] A. Bosu, A. Iqbal, R. Shahriyar, and P. Chakraborty, "Understanding the motivations, challenges and needs of Blockchain software developers: a survey," Empir. Softw. Eng., vol. 24, no. 4, pp. 2636-2673, 2019.

[17] T. Caradonna, "Blockchain and society," Informatik-Spektrum, 2020.

[18] D. Pavithran, K. Shaalan, J. N. Al-Karaki, and A. Gawanmeh, "Towards building a blockchain framework for IoT," Cluster Comput., 2020.

[19] M. Han, D. Wu, Z. Li, Y. Xie, J. S. He, and A. Baba, "A novel blockchainbased education records verification solution," in SIGITE 2018 Proceedings of the 19th Annual SIG Conference on Information Technology Education, 2018, pp. 178-183.

[20] J. Guo, C. Li, G. Zhang, Y. Sun, and R. Bie, "Blockchain-enabled digital rights management for multimedia resources of online education," Multimed. Tools Appl., 2019.

[21] D. Lizcano, J. A. Lara, B. White, and S. Aljawarneh, "Blockchain-based approach to create a model of trust in open and ubiquitous higher education," J. Comput. High. Educ., vol. 32, no. 1, pp. 109-134, Apr. 2020.

[22] S. S. Gill et al., "Transformative effects of IoT, Blockchain and Artificial Intelligence on cloud computing: Evolution, vision, trends and open challenges," Internet of Things, vol. 8, p. 100118, 2019.

[23] R. Khdhir and A. Belghith, "5G LTE-A cognitive multiclass scheduling scheme for internet of things," Int. J. Adv. Trends Comput. Sci. Eng., vol. 8, no. 5, pp. 2485-2491, 2019.

[24] J. ho Park, M. M. Salim, J. H. Jo, J. C. S. Sicato, S. Rathore, and J. H. Park, "CIoT-Net: a scalable cognitive IoT based smart city network architecture," Human-centric Comput. Inf. Sci., vol. 9, no. 1, 2019.

[25] M. S. Farooq, S. Riaz, A. Abid, K. Abid, and M. A. Naeem, "A Survey on the Role of IoT in Agriculture for the Implementation of Smart Farming," IEEE Access, vol. 7, pp. 156237-156271, 2019.

[26] M. A. Ferrag, L. Shu, X. Yang, A. Derhab, and L. Maglaras, "Security and Privacy for Green IoT-Based Agriculture: Review, Blockchain Solutions, and Challenges," IEEE Access, vol. 8, pp. 32031-32053, 2020.

[27] H. Liu, D. Han, and D. Li, "Fabric-iot: A Blockchain-Based Access Control System in IoT," IEEE Access, vol. 8, pp. 18207-18218, 2020.

[28] Z. He, Y. Zhang, B. Tak, and L. Peng, "Green Fog Planning for Optimal Internet-of-Thing Task Scheduling,” IEEE Access, vol. 8, pp. 1224-1234, 2020.

[29] S. Choi and J.-H. Lee, "Blockchain-Based Distributed Firmware Update Architecture for IoT Devices," IEEE Access, vol. 8, pp. 37518-37525, 2020

[30] C. Badii, P. Bellini, A. Difino, and P. Nesi, "Smart city IoT platform respecting GDPR privacy and security aspects," IEEE Access, vol. 8, pp. 23601-23623, 2020.

[31] K. Shafique, B. A. Khawaja, F. Sabir, S. Qazi, and M. Mustaqim, "Internet of Things (IoT) for Next-Generation Smart Systems: A Review of Current Challenges, Future Trends and Prospects for Emerging 5G-IoT Scenarios," IEEE Access, vol. 8, pp. 23022-23040, 2020.

[32] R. Morales and Y. Heredia, "Igniting the Innovation's Competencies at Engineering Schools: IoT to the Cloud Labs Network in Mexico," World Journal of Education, vol. 8, no. 2. p. 159, 2018.

[33] C. Matt, "Fog Computing: Complementing Cloud Computing to Facilitate Industry 4.0,” Bus. Inf. Syst. Eng., vol. 60, no. 4, pp. 351-355, 2018.

[34] M. De Donno, K. Tange, and N. Dragoni, "Foundations and Evolution of Modern Computing Paradigms: Cloud, IoT, Edge, and Fog," IEEE Access, vol. 7, pp. 150936-150948, 2019.

[35] F. Lin, Y. Zhou, I. You, J. Lin, X. An, and X. Lü, "Content Recommendation Algorithm for Intelligent Navigator in Fog Computing Based IoT Environment," IEEE Access, vol. 7, pp. 53677-53686, 2019.

[36] Q. Qi and F. Tao, "A Smart Manufacturing Service System Based on Edge Computing, Fog Computing, and Cloud Computing," IEEE Access, vol. 7, pp. 86769-86777, 2019.

[37] A. Raman, "Potentials of fog computing in higher education," Int. J. Emerg. Technol. Learn., vol. 14, no. 18, pp. 194-202, 2019.

[38] A. Ben Amor, M. Abid, and A. Meddeb, "Secure Fog-Based E-Learning Scheme," IEEE Access, vol. 8, pp. 31920-31933, 2020.

[39] A. Dandashi, A. Karkar, J. Aljaam, S. A. El-Seoud, and O. Ibrahim, "Framework for development of cognitive technology for children with hearing impairments," Proc. 2015 Int. Conf. Interact. Collab. Learn. ICL 2015, no. September, pp. 515-522, 2015

[40] R. Balasubramanian, A. Libarikian, and D. McElhaney, "Insurance 2030 - The impact of AI on the future of insurance," Digit. McKinsey Co., no. May, pp. 1-12, 2018. 
[41] K. Lin, C. Li, D. Tian, A. Ghoneim, M. S. Hossain, and S. U. Amin, "Artificial-Intelligence-Based Data Analytics for Cognitive Communication in Heterogeneous Wireless Networks," IEEE Wirel. Commun., vol. 26, no. 3, pp. 83-89, 2019.

[42] Y. Liu and P. Tang, "The prospect for the application of the surgical navigation system based on artificial intelligence and augmented reality," Proc. - 2018 IEEE Int. Conf. Artif. Intell. Virtual Reality, AIVR 2018, pp. 244-246, 2019.

[43] J. Estevez, G. Garate, and M. Graña, "Gentle Introduction to Artificial Intelligence for High-School Students Using Scratch,” IEEE Access, vol. 7, pp. 179027-179036, 2019.

[44] J. Suwita, R. Kosala, B. Ranti, and S. H. Supangkat, "Factors considered for the success of the Massive Open Online Course in the era of Smart Education: Systematic Literature Review," Proceeding - 2019 Int. Conf. ICT Smart Soc. Innov. Transform. Towar. Smart Reg. ICISS 2019, pp. 0-4, 2019

[45] S. Fu, F. Yang, and Y. Xiao, "AI Inspired Intelligent Resource Management in Future Wireless Network," IEEE Access, vol. 8, pp. 22425-22433, 2020.

[46] M. A. Goralski and T. K. Tan, "Artificial intelligence and sustainable development," Int. J. Manag. Educ., vol. 18, no. 1, 2020.

[47] M. Liu and L. Li, "The construction of smart campus in universities and the practical innovation of student work," ACM Int. Conf. Proceeding Ser., pp. 154-157, 2018.

[48] N. Songsom, P. Nilsook, P. Wannapiroon, C. C. Fung, and K. W. Wong, "System architecture of a student relationship management system using Internet of Things to collect digital footprint of higher education institutions," Int. J. Emerg. Technol. Learn., vol. 14, no. 23, pp. 125-140, 2019.

[49] X. Zhou, "Application Research of Face Recognition Technology in Smart Campus," 2020, vol. 1437, no. 1.

[50] A. M. Yang, S. S. Li, C. H. Ren, H. X. Liu, Y. Han, and L. Liu, "Situational Awareness System in the Smart Campus," IEEE Access, vol. 6, pp. 63976-63986, 2018.

[51] A. Majeed and M. Ali, "How Internet-of-Things (IoT) making the university campuses smart? QA higher education (QAHE) perspective," 2018 IEEE 8th Annu. Comput. Commun. Work. Conf. CCWC 2018, vol. 2018-Janua, pp. 646-648, 2018.

[52] O. Akhrif, Y. E. B. El Idrissi, and N. Hmina, "Smart university: SOCbased study," ACM Int. Conf. Proceeding Ser., 2018.

[53] L. M. Palma, M. A. G. Vigil, F. L. Pereira, and J. E. Martina, "Blockchain and smart contracts for higher education registry in Brazil," in International Journal of Network Management, 2019, vol. 29, no. 3.

[54] W. Shi et al., "Review on Development of Smart Education," Proc. - IEEE Int. Conf. Serv. Oper. Logist. Informatics 2019, SOLI 2019, pp. 157-162, 2019.

[55] S. Yuxia, "Researches on the Construction of the Smart Campus System with respect to the Higher Vocational Colleges in the Information AgeTaking Dalian Vocational and Technical College as an Example," J. Phys. Conf. Ser., vol. 1437, no. 1, 2020.

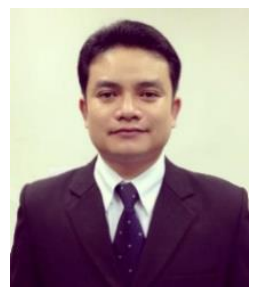

Sakchai Chaiyarak is a lecturer at the Faculty of Education, Suan Dusit University. He received the B.Ed. in Computer Education and received the M.Ed. in Administration of Education. He currently field of expertise are ICT, learning management and pedagogy. His research interests focus on Artificial Intelligence (AI), Cognitive Technologies, Cloud Computing, Internet of Things (IoT), Blockchain, and Digitalized Learning. (e-mail: chaiyaraks@gmail.com, sakchai_cha (a)dusit.ac.th)

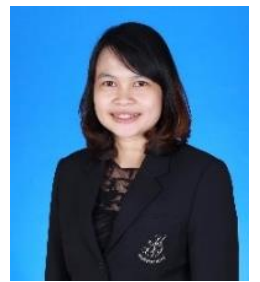

Alongkorn Koednet is a lecturer at the Faculty of Education, Suan Dusit University. She received the B.Ed. in Computer Education and received the M.Ed. in Administration of Education. She currently field of expertise are pedagogy, learning management and classroom management. Her research interests focus on Personalized learning, Adaptive learning, Microteaching, ICT to enhance design of learning management for pre-service teachers in the $21^{\text {st }}$ century. (e-mail: alongkorn_koe@dusit.ac.th,koykoi1522@gmail.com)

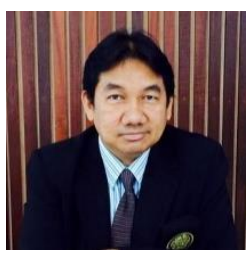

Prachyanun Nilsook is an Associate Professor at the Division of Information and Communication Technology for Education, King Mongkut's University of Technology North Bangkok (KMUTNB), Thailand. He currently works in the field of ICT for Education and Vocational Education Technology Research Centre. He is a member of Professional Societies in the Association for Educational Technology of Thailand (AETT) (e-mail: prachyanunn@kmutnb.ac.th, prachyanun@hotmail.com)

\section{Creative Commons Attribution License 4.0 (Attribution 4.0 International, CC BY 4.0)}

This article is published under the terms of the Creative Commons Attribution License 4.0 https://creativecommons.org/licenses/by/4.0/deed.en_US 